2 Separation Science and Technology, Volume 46, Issue 16, 2011, pp2489-2495

3

4

5

6

7

8

9 17

\section{organic matter \\ Ballasted flotation with glass microspheres for removal of natural}

Peter Jarvis $^{+*}$, John Martin**, Tracey Winspear ${ }^{* * *}$ and Bruce Jefferson* *Centre for Water Science, Cranfield University, Bedford, MK43 OAL, UK

**Christ Kennicott Water Technology Ltd now part of OVIVO, Wednesfield, Wolverhampton, WV11 1XR, UK ***Trelleborg OCP Limited, Barrow-in-Furness, Cumbria, LA14 2PE, UK ${ }^{+}$Corresponding author: p.jarvis@ @ cranfield.ac.uk 16 


\section{Abstract}

19 Low density microspheres were used to float flocs formed from the coagulation of natural 20 organic matter (NOM) using ferric sulphate coagulant. Microspheres were visually 21 observed to be incorporated into the floc structure during the coagulation phase. In 22 comparison with conventional flotation with air bubbles, the residual turbidity after

23 flotation using the microspheres was very favourable and did not impact on overall NOM 24 removal. Spheres of the lowest density and largest particle size gave the most rapid floc 25 clearance, but the residual turbidity after 10 minutes flotation was similar for all of the 26 spheres investigated. The results of this work have shown that floating microspheres offer 27 an effective, energy efficient alternative to conventional dissolved air flotation for 28 removal of flocs containing high concentrations of NOM.

29

30 Keywords: ballasted flotation, Flocs, low energy, natural organic matter, flotation, 31 dissolved air flotation. 


\section{Introduction}

Enhanced clarification through the use of ballasting agents is common place in the water industry. In recent times the embodiment of this concept has focussed on enhancing sedimentation through incorporation of sand [1], sludge [2] or magnetic particles [3] resulting in hydraulic loading rates (surface overflow rate - SOR) up to 40-60 times higher than traditionally experienced with sedimentation $\left(1-2 \mathrm{~m}^{3} \mathrm{~m}^{-2} \mathrm{~h}^{-1}\right)$. However, the earliest ballasting agent to be routinely used was air bubbles in the dissolved air flotation (DAF) process [4]. The process operates by forming micro bubbles of air in the size range 40-100 $\mu \mathrm{m}$ [5] through depressurisation of air saturated water passing through a nozzle. The generated bubble cloud then combines with the pre formed flocs, reducing their effective density causing the combined flocbubble aggregate to rise to the surface. The requirement to lower the density of the floc to below that of water means that the process is primarily utilised for removal of naturally low density pollutants such as algae and natural organic matter (NOM).

A major advantage of all ballasting systems is their inherent flexibility as the clarification rate is linked to the dose of ballasting agent applied. In the case of the DAF process the number of bubbles released is controlled by the combination of the super saturation pressure and the flow rate through the saturation tank. The latter is more commonly used to control the process and is known as the recycle ratio as it uses post clarified water which is then returned to the DAF process. Corresponding surface overflow rates range between $5-40 \mathrm{~m}^{3} \mathrm{~m}^{-2} \mathrm{~h}^{-1}[5,6]$ although operational practice with natural organic matter is normally closer to $4-8 \mathrm{~m}^{3} \mathrm{~m}^{-2} \mathrm{~h}^{-1}$ due to concerns over floc breakage [7]. As with all ballasting systems, the improved performance and flexibility is balanced against a need for additional infrastructure and increased operating costs associated with managing the ballasting agent. In the case of 
58 DAF, the key issue is related to the generation of the micro bubbles which requires pumping recycle flow under pressures of between 4-6 bar. Associated energy estimates range between $0.01-0.03 \mathrm{kWh} \mathrm{m}^{-3}$ [8] which accounts for between $50-90 \%$ of the total energy demand associated with the process $[9,10]$.

Conceptually, the same benefits can be realised using low density microspheres instead of air bubbles in a technology more akin to the use of sand in ballasted sedimentation [1]. In such cases the microspheres can be used to further enhance the clarification rates when used in combination with air bubbles or reduce the energy of operation when used as the sole ballasting agent. The latter idea has been detailed in two patents: WO/2006/008474 [11] and US Patent 6890431 [12], however published work verifying the concept is limited.

69 The current paper investigates this idea by assessing the potential to use low density 70 glass microspheres as a flotation ballasting agent for the clarification of NOM flocs. A 71 previous study has demonstrated the potential of the idea for algae flocs where 72 removal efficiencies of between $63-97 \%$ were observed when using $100 \mu \mathrm{m}$ glass 73 microspheres with no additional air [13]. The highest removal was seen for 74 Microcystis and the lowest for Chlorella indicating that organic matter components 75 were likely to be important as the algae are fairly similar in size. As NOM exists 76 predominantly in dissolved or colloidal states, organic matter interactions are 77 expected to be even more important. Consequently, the paper addresses the current 78 knowledge gap by assessing the potential for use of microspheres in the treatment of a 79 NOM-laden water, a water that is typically treated using DAF technology. In addition 80 to assessing the overall potential of using the micropsheres for NOM removal, the 81 investigation considers the impact of dosing regime and microsphere incorporation 82 into the floc to resolve practical issues associated with developing the technology. 
84 A series of bench scale tests were carried out to determine the feasibility of using microspheres for treatment of NOM laden waters. This consisted of: 1) jar testing to determine removal of the NOM and 2) microsphere and floc characterisation to determine the physical characteristics of the flocs formed and the microspheres dosed during coagulation.

\section{Jar testing}

90 Jar tests were carried out using a model DBT6 DAF batch jar tester (EC Engineering,

91 Canada). The DAF jar tester operates in a similar way to a standard jar tester during

92 the floc formation stage. One-Litre (1-L) samples of raw water were placed in 1-L 93 square beakers after the addition of Fe coagulant (ferric sulphate - Ferripol XL, EA 94 West). Water was rapid-mixed for 1.5 minutes at $200 \mathrm{rpm}$ followed by a slow stir 95 period at $30 \mathrm{rpm}$ for 15 minutes. Unlike on a standard jar tester, where sedimentation 96 is used to separate the formed floc from the water, the DAF jar tester adds air 97 saturated water pressurised at $450 \mathrm{kPa}$ into the jar. At the lower pressure in the jar, air 98 bubbles precipitate and attach to the flocs in the jar and float to the surface. The 99 amount of air saturated water added into the jar can be varied from $0-20 \%$ of the 1-L

100 sample in the jar (subsequently referred to as the recycle ratio). Water was sampled 101 from the jar at a sampling point a third of the way up the jar at time intervals of 1,5 102 and 10 minutes of flotation for conventional DAF jar tests (no microspheres added).

103 For systems where microspheres were used, no air was added. Tests were also carried 104 out on the jar tester without the addition of microspheres and air for a traditional 105 sedimentation test, as the flocs formed were more dense than water. 
107 The water tested on was sampled from a water treatment works (WTWs) in the north

108 of the UK that was considered to be characteristic of a NOM-laden water being of a

109 brown colour, as a result of the high humic content of the water, and low turbidity.

110 The water correspondingly had a dissolved organic carbon (DOC) content of $10.6 \mathrm{mg}$

$111 \mathrm{~L}^{-1}$; ultraviolet absorbance at $254 \mathrm{~nm}\left(\mathrm{UV}_{254}\right)$ of $0.45 \mathrm{~cm}^{-1}$; turbidity of $1-4 \mathrm{NTU}$ and

112 alkalinity of $<20 \mathrm{mg} \mathrm{L}^{-1} \mathrm{CaCO}_{3}$. Water was coagulated using ferric sulphate (Ferripol

$113 \mathrm{XL}, \mathrm{EA}$ West) at $\mathrm{pH} 4.5$ (a pre-determined optimum for this water) [5, 14].

\section{Microsphere dosing}

115 Initial experiments used SID $350 \mathrm{Z}$ microspheres (commercially known as

116 Eccospheres ${ }^{\circledR}$ from Trelleborg, Emerson and Cuming Inc, USA). The hollow spheres

117 are composed of a thin shell made from sodium borosilicate glass. This type of glass

118 has a lower density and higher chemical and thermal stability when compared with

119 silicate glass. Manufacturer information reported the densities of the microspheres as

$120 \quad 0.35 \mathrm{~g} \mathrm{~cm}^{-3}$ with a median particle size of $50 \mu \mathrm{m}$. The microspheres were used in

121 coagulation tests as provided by the manufacturer. Later tests used the following

122 microspheres (density and median diameter in brackets): SI $100\left(0.10 \mathrm{~g} \mathrm{~cm}^{-3}, 70 \mu \mathrm{m}\right)$;

123 SI $160\left(0.16 \mathrm{~g} \mathrm{~cm}^{-3}, 62 \mu \mathrm{m}\right)$; SI $200\left(0.20 \mathrm{~g} \mathrm{~cm}^{-3}, 55 \mu \mathrm{m}\right)$.

124 The different experimental dosing parameters investigated were: coagulant

125 concentration $\left(0-20 \mathrm{mg} \mathrm{L}^{-1} \mathrm{Fe}\right)$, microsphere concentration (0-450 mg/L SID 350),

126 microsphere dosing sequence and different microsphere variants (density and particle 127 size). 


\section{Sampling and analysis}

129 For each jar test, samples were analysed for turbidity using a Hach 2100 turbidimeter

130 after 1, 5 and 10 minutes of flotation. During the testing of increasing coagulant dose,

131 samples were also analysed for residual DOC and $\mathrm{UV}_{254}$ using a Shimadzu 5000A

132 TOC analyser and a Jenway UV/Vis spectrophotometer respectively.

134

135

136

\section{Physical characterisation of microspheres and floc}

The particle size distribution (PSD) of the microspheres used in this work was measured using a laser diffraction instrument: Malvern Mastersizer 2000 (Malvern Instruments). Microspheres were added into 1-L of de-ionised (DI) water in a 1-L square beaker at a concentration of $300 \mathrm{mg} \mathrm{L}^{-1}$. The microspheres were mixed on a jar tester at $200 \mathrm{rpm}$ and pumped through the optical unit of the Mastersizer and back into the jar. An average of three measurements was used to provide the final PSD.

The clearance rate of the different microspheres was measured by adding $300 \mathrm{mg} \mathrm{L}^{-1}$ of the microspheres into 1-L of DI water in 1-L square beakers and turbidity was measured from the sampling port in the jar after 10 minutes flotation.

The physical characteristics of the flocs formed with and without microsphere addition were measured using the Mastersizer instrument. Floc formation tests were carried out on a jar tester. After the slow stir at $30 \mathrm{rpm}$, the effect of increased shear rate was investigated by increasing the rpm on the jar tester to $200 \mathrm{rpm}$ for a further 15 minutes. The shear rate was then reduced back to $30 \mathrm{rpm}$ for 15 minutes to determine the floc re-growth potential. Dynamic floc size was measured during growth, breakage and re-growth of the flocs using the Mastersizer. The suspension was monitored by drawing water through the optical unit of the Mastersizer and back into the jar by a peristaltic pump on the return tube using $5 \mathrm{~mm}$ internal diameter 
153 peristaltic pump tubing at a flow rate of $1.5 \mathrm{~L} \mathrm{hr}^{-1}$. Size measurements were taken

154 every minute for the duration of the jar test and logged onto a PC. Flocs were also

155 characterised by investigation under a light microscope (Olympus) to determine the

156 effectiveness of microsphere incorporation into the floc.

157

158 Results

159 Microsphere characterisation

160 The median diameter of the different microspheres (manufacturers rated size in

161 brackets) based on a volume based measurement was $39,71,71$ and $68 \mu \mathrm{m}$ for the

162 SAD $350 Z(50 \mu \mathrm{m})$, SI $100(70 \mu \mathrm{m})$, SI $160(62 \mu \mathrm{m})$ and SI $200(55 \mu \mathrm{m})$ spheres

163 respectively. For most of the microspheres, the PSD was closely distributed around

164 the median values given. The exception was the SI 100 spheres which had a much

165 wider particle size distribution with values ranging between $26-158 \mu \mathrm{m}$. Addition of

166 the microspheres into a standard jar testing beaker filled with deionised water

167 revealed that, as expected, the resultant residual turbidity was related to the density of

168 the microspheres. The initial turbidity due to inclusion of the microspheres was 95

169 NTU which decreased to 0.4 NTU for the SI 100 microspheres (density $\left.=0.1 \mathrm{~g} \mathrm{~cm}^{-3}\right)$.

170 Residual turbidity for the other microspheres were 0.5 NTU for the SI160 (density =

$1710.16 \mathrm{~g} \mathrm{~cm}^{-3}$ ) and the SI $2000\left(\right.$ density $\left.=0.3 \mathrm{~g} \mathrm{~cm}^{-3}\right)$. The highest density microspheres

172 of $0.35 \mathrm{~g} \mathrm{~cm}^{-3}$ (SID 350Z) left a residual turbidity of 0.7 NTU.

\section{Coagulation performance}

174 Comparison of effectiveness of coagulation with and without the presence of SID

$175350 \mathrm{Z}$ microspheres revealed no significant difference between the two indicating that

176 the microspheres did not inhibit coagulation or exert an additional demand for

177 coagulant (Figure 1). In both cases, the removal of $\mathrm{UV}_{254}$ and DOC followed the same 
178 trend with an increase in removal with coagulant dose up until a dose of $8 \mathrm{mg} \mathrm{L}^{-1} \mathrm{Fe}$.

179 At coagulant concentrations above this, removals did not improve. Residual DOC was

$1802 \mathrm{mg} \mathrm{L}^{-1}$, an $83 \%$ reduction. $\mathrm{UV}_{254}$ was reduced to $0.024 \mathrm{~cm}^{-1}$, a decrease of $95 \%$.

181 These removals were consistent with previous observations when using this water [5,

182 14]. Subsequent coagulation trials were therefore carried out using a ferric sulphate 183 concentration of $8 \mathrm{mg} \mathrm{L}^{-1}$ as Fe.

184 Alteration of the dose of SID $350 \mathrm{Z}$ microspheres decreased the resultant turbidity up 185 to dose limit of $150 \mathrm{mg} \mathrm{L}^{-1}$ beyond which increasing the dose further had no impact

186 on the residual turbidity (Figure 2). To illustrate, residual turbidity increased from 2.3

187 NTU at a microsphere dose of $0 \mathrm{mg} \mathrm{L}^{-1}$ (equivalent to the comparative residual 188 turbidity observed for a sedimentation system) to $5.7 \mathrm{NTU}$ with a dose of $50 \mathrm{mg} \mathrm{L}^{-1}$ 189 after 15 minutes of clarification. The residual turbidity then decreased to 1.6 NTU at a 190 dose of $150 \mathrm{mg} \mathrm{L}^{-1}$ before decreasing slightly to $1.3 \mathrm{NTU}$ at a dose of $450 \mathrm{mg} \mathrm{L}^{-1}$.

191 Visual observation of the trial verified that inclusion of the microspheres resulted in

192 flotation compared with sedimentation without microspheres (Figure 3) as seen by the 193 generation of a float layer that remained stable post clarification.

\section{Impact of operational decisions}

196 A key feature with all ballasting technologies is the sequence of additions with

197 regards to the coagulant and the ballasting agent. A series of trials was conducted to

198 establish the impact of dosing sequence to reflect the different operational practices

199 reported for systems that used other ballasting agents [15, 16]. Optimum removal 200 under each dosing strategy revealed that simultaneous dosing of coagulant and 201 microsphere provided the most effective method of microsphere incorporation and 202 resultant residual turbidity (Figure 3). For instance, dosing the microspheres 1 minute 
203 after the coagulant resulted in a 1 NTU increase in residual turbidity. This was 204 attributed to reduced microsphere incorporation into the floc because the aggregates 205 had already started to form before the microspheres had been added. In contrast, 206 ballasting with sand is conducted post floc formation where the mass of the sand 207 relative to the floc is thought to enable the sand to enter into the floc structure [15]. In 208 such cases a chemical addition occurs at two points: initially to drive floc formation 209 and post sand inclusion to aid binding. In the current case this idea was tested through 210 multi coagulant doses where either the total dose was kept constant (4+4) or the full 211 dose used at each injection point (8+8) (Figure 3). In both cases the residual turbidity 212 improved to 1.9 and 2.3 NTU respectively but remained higher than the base case of 213 simultaneous dosing. It is also common to utilise ballasting agents when coagulating 214 in high $\mathrm{pH}$ environments which favour sweep flocculation mechanisms. Residual 215 turbidity under such conditions $(\mathrm{pH}=8.5)$ resulted in a deterioration of performance 216 leading to a residual turbidity of 6.7 NTU. Comparison across the different options 217 suggests that the microspheres should be injected prior to, or simultaneously with, the 218 coagulant to ensure maximum incorporation into the floc. This is consistent with the 219 overall understanding of coagulation of NOM laden waters such as the one tested in 220 the current investigation. Previous investigations into coagulation have shown that 221 floc growth is rapid and that floc size reaches a steady state value typically within 5 222 minutes after coagulant injection with substantial growth being evident within the first 223 two minutes of coagulation [17]. Consequently, post addition of microspheres after 224 coagulation restricts the potential for microsphere incorporation resulting in less even 225 spread of microspheres throughout the aggregates and less total incorporation. 226 Comparison with the mechanism proposed for sand inclusion into flocs indicates that 227 the low density of the microspheres is unlikely to have sufficient momentum to drive 
post flocculation incorporation and hence the need to be incorporated as the flocs initially form for maximum inclusion.

231 The other major operational decision in relation to ballasted flotation relates to the 232 selection of the most effective microsphere. Comparison of the different microspheres 233 tested revealed no significant different between the residual turbidity after 10 minutes 234 of clarification at between 1 and 1.3 NTU (Figure 4). In comparison, operation of the 235 jar tester in standard DAF (equivalent recycle ratio of $4 \%$ ) or sedimentation mode 236 resulted in a residual turbidity of 0.8 NTU and 1.8 NTU respectively indicating that 237 the ballasted microsphere systems performed effectively. To reflect that both the size 238 and density of the microspheres were changing, the residual turbidity was compared 239 with the lumped parameter $\Delta \rho d^{2}$ based around Stokes' law where $\Delta \rho$ is the difference 240 in density between the water and the microsphere and $\mathrm{d}$ is the diameter of the 241 microsphere (Figure 5). Comparison of the data revealed that microsphere properties 242 had minimal influence on residual turbidity after 10 minutes of clarification. In 243 contrast, microsphere properties were seen to strongly influence performance over 244 short clarification times. For instance, after 1 minute of clarification the highest $\Delta \rho d^{2}$ 245 value of $4.5 \times 10^{-6} \mathrm{~kg} \mathrm{~m}^{-1}$ generated the lowest the residual turbidity of $2.5 \mathrm{NTU}$. 246 Residual turbidity reached a maximum of $15.9 \mathrm{NTU}$ as the $\Delta \rho d^{2}$ decreased to $3.7 \times 10^{-6}$ $247 \mathrm{~kg} \mathrm{~m}^{-1}$. At the lowest value of $\Delta \rho d^{2}$ at $9.9 \times 10^{-7} \mathrm{~kg} \mathrm{~m}^{-1}$ a residual turbidity of $10.5 \mathrm{NTU}$ 248 was observed. After 5 minutes flotation time, the same trend in residual turbidity was 249 observed for the same $\Delta \rho d^{2}$ as for 1 minute flotation, but there was less difference 250 between the highest and lowest turbidity. 
252 Monitoring of floc growth dynamics with and without microsphere inclusion revealed 253 that the inclusion of microspheres did not influence the initial growth rate but reduced 254 the steady state floc size achieved (Figure 6). To illustrate, flocs reached a maximum 255 median diameter of $750 \mu \mathrm{m}$ when no microspheres were added compared with 590 $256 \mu \mathrm{m}$ with microsphere inclusion. In addition, inclusion of microspheres did not result 257 in any difference in terms of the impact of increased shear rate and subsequent re258 growth of the floc with both systems decreasing to $160 \mu \mathrm{m}$ when exposed to a shear 259 rate of $200 \mathrm{rpm}\left(\mathrm{G}=127.5 \mathrm{~s}^{-1}\right)$ and re-growing to a size of $200 \mu \mathrm{m}$ when the shear 260 rate was reduced to $30 \mathrm{rpm}\left(\mathrm{G}=7.4 \mathrm{~s}^{-1}\right)$ for a further 15 minutes (Figure 6).

261 Visual inspection of the aggregates revealed that the microspheres were successfully 262 incorporated into the floc and where distributed throughout the floc structure 263 (Example provided as an insert in Figure 6). In addition, visual inspection of the jars 264 post clarification suggested that the ballasted system was performing better than the 265 standard DAF version. Closer inspection revealed that the main contribution to the 266 residual turbidity was microspheres that had not been incorporated into the 267 aggregates. This was confirmed by filtering the residual water through a $450 \mathrm{~nm}$ filter 268 which collected the unincorporated microspheres. The retained free microsphere 269 appeared to have no organic coating or coagulant associated to them which was 270 interpreted as microsphere that had not been incorporated within the floc during 271 flocculation as opposed to release of beads during floc breakage.

\section{Discussion}

273 The results of this work have demonstrated the potential to use low density 274 microspheres as a ballasting agent for flotation. Comparison with traditional DAF 
indicates similar levels of removal for NOM treatment such that use of microspheres can be considered as an alternative to bubbles for operation of a low energy, lower carbon footprint alternative to traditional DAF due to removing the need for a saturation system. Estimates of energy demand associated with saturation range between 0.01-0.04 $\mathrm{kWh} \mathrm{m}^{-3}[8,9]$ with equivalent numbers for hydrocyclones 280 suggesting between a 60-80 \% energy saving if ballasted flotation was adopted [18]. 281 Placed into the context of a medium size water treatment works $\left(50 \mathrm{ML} \mathrm{d}^{-1}\right)$ this 282 equates to a saving of, based on an average value of energy demand, 365,000 kWh 283 year ${ }^{-1}$ which represents a cost reduction of $£ 25,550$ year $^{-1}$ (based on electricity costs 284 of $7 \mathrm{p}$ per $\mathrm{kWh})$ or $198.6 \mathrm{tCO}_{2} \mathrm{e}$ year ${ }^{-1}\left(0.544 \mathrm{kgCO}_{2} \mathrm{e} \mathrm{kWh}\right)$. Extending this across 285 multiple DAF plants represents a significant saving to an individual water company.

286 The presented results also offer insight into key design and operating issues. In terms 287 of microsphere selection, the combined term $\Delta \rho d^{2}$ can be used to grade appropriate 288 microspheres. Little difference was observed for longer clarification periods but clear 289 advantage when using high $\Delta \rho d^{2}\left(>4 \times 10^{-6} \mathrm{~kg} \mathrm{~m}^{-1}\right)$ was seen when operating on short 290 clarification periods. The explanation relates to the microsphere numbers required to 291 achieve suitable rise velocities. Typical floc rise velocities of bubble-floc aggregates 292 have been measured between 3 and $15 \mathrm{~m} \mathrm{~h}^{-1}[19,20]$. Based on flocs having an 293 average diameter of $500 \mu \mathrm{m}$, with a conservative density of the flocculated material of $2941050 \mathrm{~kg} \mathrm{~m}^{-3}$ and assuming that the flocs are spherical in nature and obey Stokes' law, 295 for a target rise velocity of $6 \mathrm{~m} \mathrm{~h}^{-1}$ only 12 of the bigger, lower density SI 100 296 microspheres would need to be contained in the floc. For the smaller, lower density 297 spheres approximately 150 of the SI $350 Z$ microspheres would need to be contained 298 in each floc aggregate to achieve the same rise velocity. This explains why the 299 increased turbidity was much greater after 1 and 5 minutes for the smaller, higher 
density spheres: not enough microspheres were incorporated into the floc to give

301 comparable rise velocities as for the large, low density spheres. After 10 minutes, the

302 floc-microsphere aggregates, and any residual microspheres, had had enough time to

303 clear from the water.

304 The other major observation concerning application of microspheres is related to

305 dosing sequence where optimum performance was observed when the microspheres

306 were incorporated during the initial floc growth stages. This is in contrast to

307 traditional DAF where the air bubbles combine with the pre formed floc [21] or sand

308 which is combined with partially formed flocs and bound with additional chemicals

309 [1]. In the current case, post floc incorporation is limited as the microspheres have

310 insufficient mass to penetrate the formed flocs due to their momentum [15]. The

311 consequence of which is that dosing arrangements require careful management when

312 using microspheres. The ideal arrangement would be injection of microspheres into

313 the incoming feed line to ensure effective mixing with the water prior to the initiation

314 of flocculation [13].

\section{Conclusions}

317 The overall conclusion from the work is that the application of glass microspheres as 318 a ballasting agent is an effective alternative to DAF. The use of microspheres provides 319 a route to significantly reduce the energy and carbon footprint of flotation whilst 320 retaining the treatment efficiency. Selection of the most appropriate bead appears only 321 crucial when operating at very short residence times such that the main area for 322 optimisation and control relates to microsphere incorporation into the floc. This is 323 best achieved through pre-dosing the microsphere prior to chemical addition which 324 then ensures both good incorporation and even distribution. Whilst the current work 
325 demonstrated the potential for using microspheres, further work is required to resolve

326 the operational issues that will ensure the process becomes and effective technology 327 in the future.

\section{References}

330 1. Plum, V.; Dahl, C. P.; Bentsen, L.; Petersen, C. R.; Napstjert, L.; Thomsen, N. B. 331 (1998) The actiflo method, Water Science and Technology, 37: 269-275.

332 2. Landon, S.; Donahue, C.; Jeyanayagam, S.; Craden, D. (2006) Rain check: 333 Columbus, Ohio, considers ballasted flocculation to treat its wet weather flows. Water Environment and Technology, 18: 30-35.

335 3. Dixon, D. R. (1991) The sirofloc process for water clarification. Water Supply, 9: $33-36$.

4. Gorczyca, B.; Zhang, G. (2007) Floc size distributions in dissolved air flotation of Winnipeg tap water, Environmental Technology, 28: 243-254.

5. Edzwald, J. K. (1995) Principles and applications off dissolved air flotation. Water Science and Technology, 31: 1-23.

341 6. Arnold, S.; Grubb, T.; Harvey P. (1995) Recent applications of dissolved air 342 flotation pilot studies and full scale design. Water Science and Technology, 31 (34): $327-340$.

7. Jarvis, P.; Jefferson, B; Parsons, S. A. (2005) How the natural organic matter to coagulant ratio impacts on floc structural properties. Environmental Science and Technology, 39: 8919-8924.

8. Crossley, I. A.; Valade, M. T. (2006) A review of the technological developments of dissolved air flotation. Journal of Water Supply Research and Technology AQUA, 55: 479-491. 
350 9. Feris, L. A.; Rubio, J. (1999) Dissolved air flotation (DAF) performance at low saturation pressures. Filtration and Separation, 31: 61-65.

352 10. Watts, M. (2011) Dissolved air flotation cost effective saturation. $353 \quad$ www.wrcplc.co.uk/pdf/mark_watts.pdf [last accessed 15/02/2011]

354 11. Woodbridge, Patent No: WO/2006/008474 (2006). Flotation process and 355 apparatus for separating suspended particles from a liquid.

356 12. Vion, P. (2000) US Patent 6277285, Process for the clarification of liquids and 357 suspensions.

358 13. Jarvis, P.; Buckingham, P.; Holden, B.; Jefferson, B. (2009) Low energy 359 ballasted flotation, Water Research, 43: 3427-3434.

360 14. Sharp, E. L.; Parsons, S. A.; Jefferson, B. (2006) The impact of seasonal 361 variations in DOC arising from a moorland peat catchment on coagulation with 362 iron and aluminium salts. Environmental Pollution, 140: 436-443.

363 15. Ghanem, A. V.; Young, J. C.; Edwards, F. G. (2007) Mechanisms of ballasted 364 floc formation. Journal of Environmental Engineering, 133: 271-277.

365 16. Fabris, R.; Chow, C. W. K.; Drikas, M. (2004) Practical application of a 366 combined treatment process for removal of recalcritrant NOM - Alum and PAC. 367 Water Science and Technology - Water Supply, 4: 89-94.

368 17. Jarvis, P.; Jefferson, B.; Parsons, S. A. (2006) Floc structural characteristics using 369 conventional coagulation for a high doc, low alkalinity surface water source. $370 \quad$ Water Research, 40: 2727-2737.

371 18. Svarovsky, L. (2001) Solid-Liquid Separation, $4^{\text {th }}$ Ed.: Butterworth-Heinemann: 372 Oxford, UK. 
373 19. Vlaški, V.; Van Breemen, A. N.; Alaerts, G. J. (1997) The role of particle size and density in dissolved air flotation and sedimentation, Water Science Technology, 36 (4): 177-189.

376 20. Ljunggren, M.; Jonsson, L.; La Cour Jansen, J. (2004) Particle visualisation - a 377 tool for determination of rise velocities. Water Science and Technology, 50 (12): 229-236.

379 21. Henderson, R. K.; Parsons, S. A.; Jefferson, B. (2008) Surfactants as bubble 380 surface modifiers in the flotation of algae: Dissolved air flotation that utilizes a 381 chemically modified bubble surface. Environmental Science and Technology, 42: $382 \quad 4883-4888$. 